\title{
BCCM4
}

\section{EFFECT OF THE FILAMENT WINDING PATTERN MODELING ON THE AXIAL COMPRESSION OF CYLINDRICAL SHELLS}

\author{
Cristiano B. de Azevedo ${ }^{(1)}$, Frederico Eggers ${ }^{(1)}$, José H. S. Almeida Jr. ${ }^{(2)}$ and Sandro C. \\ Amico (1)
}

(1) PPGE3M, Federal University of Rio Grande do Sul, Brazil

(2) Leibniz-Institut für Polymerforschung (IPF) e.V., Dresden, Germany

https://doi.org/10.21452/bccm4.2018.09.05

\begin{abstract}
Manufacturing characteristics of the filament winding process, such as the formation of a winding pattern, are usually disregarded in conventional numerical models. However, they could significantly affect stress and strain fields in thin-walled composite shells. This work presents an efficient way to realistically model the filament winding mosaic pattern in composite cylindrical shells under axial compression. The study comprises the linear finite element (FE) Eigenvalue and Eigenvector buckling model of thin-walled composite cylindrical shells using commercial software. A conventional model was developed and an optimization algorithm was used to find the highest Eigenvalue. After the optimum fiber angle was found, it was used for winding pattern drawing and modeling. Three winding patterns were modeled: $1 / 1,3 / 1$ and $5 / 1$, where the numerator means the number of diamonds around the number of circumferences indicated by the denominator. The optimum angle-ply fiber layout found was $[ \pm 30]$, which reached the highest critical buckling load. The winding pattern influenced the critical buckling load, and the 1/1,3/1 and 5/1 patterns showed critical buckling loads of $11.237,11.173$ and $11.194 \mathrm{kN}$, respectively, whereas the conventional modeling approach indicates a critical load of $8.574 \mathrm{kN}$.
\end{abstract}

\section{INTRODUCTION}

Among the manufacturing processes available for polymer composites, filament winding (FW) stands out due to high accuracy in fiber positioning, high fiber volume fraction, low void content and process automation. Cylindrical structures, such as tubes and pressure vessels made by FW are being increasingly used in aeronautical, marine and automotive sectors. The high design freedom and the intrinsic orthotropy of long-fiber-reinforced composites provide numerous possibilities to decrease weight while fulfilling the load requirements [1]. Key parameters in FW process include winding angle, wall thickness and filament winding pattern [2]. 
Among the FW process parameters, the winding pattern number is usually disregarded in conventional numerical models since it requires complex and work-intensive modelling to accurately simulate the fiber path. This pattern is the main intrinsic parameter that controls fiber inter-crossing, and is typically determined as an $\mathrm{X} / \mathrm{Y}$ fraction, where $\mathrm{X}$ represents the winding cycle and $\mathrm{Y}$ the bandwidth, i.e. for each $\mathrm{X}$ cycles, there is a $\mathrm{Y}$ band advance.

One cycle is characterized as a complete movement from beginning to end and the returning to the initial point on the mandrel. The winding process occurs through regular and repetitive movements of a pay-out eye that deposits the tow onto the mandrel. The first pass of the cycle has a positive winding angle, and the returning follows the same winding angle but negative. This way, the mandrel is covered twice and only an even number of layers are possible, forming an angle-ply $\pm \alpha$ layer. The number of cycles depends on the degree of covering and the tow width [3]. Due to the repetitive movements, the layout of the layer is characterized by the distinctive regular mosaic pattern consisting of triangular-shaped, repeating in chess-board fashion, two-ply units. The units are arranged in regular geometric pattern around the circumference and along the axis of rotation [4].

Several studies were carried out in order to determine the influence of FW parameters on the mechanical behavior of structures. For instance, Krishnan et al. [5] evaluated the influence of the winding angle in composite tubes subjected to multiaxial cyclic pressure loadings. Failure envelopes showed a strong dependence on stress ratio and winding angle, with $[ \pm 45]_{4}$, tending to be axially dominant, and $[ \pm 63]_{4}$ performing better under high hoop-dominant loading. Almeida Jr. et al. [6] developed an optimization procedure based on a genetic algorithm to determine the best stacking sequence in composite tubes under internal pressure loading. They found that asymmetrical and unconventional angles increase the burst strength for internally pressurized tubes. Other studies in the literature have reported the influence of the winding angle in composite tubes under compression loading $[7,8]$ and composite rings under tensile loading $[9,10]$.

Among the very few works in the literature dealing with winding pattern modeling, Morozov [4] numerically evaluated the influence of the winding pattern on tubes subjected to internal pressure. The stress fields were sensitive to the winding pattern and conventional models using nominal angle underestimated the stresses. Other studies reported the influence of the winding pattern on the mechanical behavior of composite tubes [11], pressure vessels [12] and flywheel disk [13].

This work aims at proposing a novel and efficient methodology to model the winding pattern in composite cylindrical shells. The influence of the winding pattern is evaluated with respect to the cylindrical shells under axial compressive load.

\section{FINITE ELEMENT MODELING}

\subsection{Winding pattern generation}

A numerical model that incorporates the winding pattern has been developed on Python language due to its excellent compatibility with the FE software herein used, Abaqus $6.14^{\mathrm{TM}}$. Another advantage is related to the use of trigonometric ratios to define the exact positioning of the lines that will form the winding pattern. The essence of model development consists on creating lines in datum planes and projecting them onto the surface of the cylinder to produce the winding pattern. Since the script uses functions common to other CAD platforms, the script can be easily adapted to other languages (e.g. C\# or VBA).

The first step is to model a cylinder with radius $r$ and length $l$, axially coincident with the z-axis (Fig. 1a). Then, the first datum plane is created where the lines that make the pattern are inserted (Fig. 1b, and detailed in Fig. 2). The lines are projected onto the tube surface (Fig. 1c). In order to avoid distortions, the process is done in four planes of reference around the tube, changing only the positioning of the lines. Finally, a datum plane is used for the 
insertion of vertical lines (Fig. 1d), which will delimitate the hoop-wound reinforcement regions, and the lines that divide the diamonds into triangular regions (Fig. 1e).

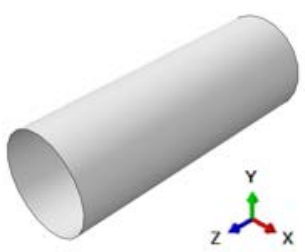

(a)

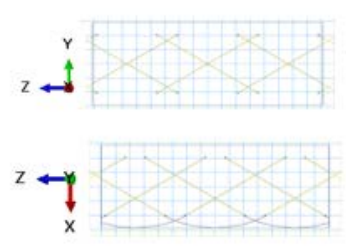

$\mathrm{z}$

$2 \stackrel{x}{f}$
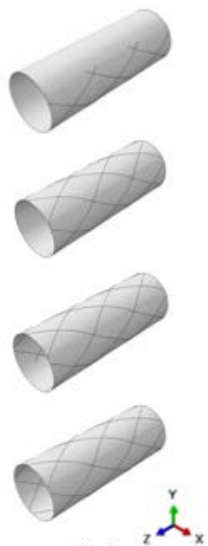

(c)

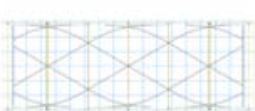

(d)

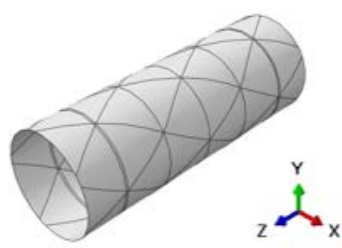

(e)

(b)

Figure 1 - Development stages of a particular winding pattern modeling: (a) cylinder modeling, (b) datum plane creation, (c) projection onto the tube surface, (d) insertion of vertical lines and (e) complete tube modeling.

The lines that make the winding pattern (Fig. 1b) start from a reference line between the points $\left(x_{0}, y_{0}\right)$ and $\left(x_{1}, y_{1}\right)$, with coordinates $(-\Delta x,-\Delta y)$ and $(+\Delta x,+\Delta y)$, respectively (Fig. 2), where $\Delta y$ and $\Delta x$ are determined by Eqs. 1 and 2, respectively.

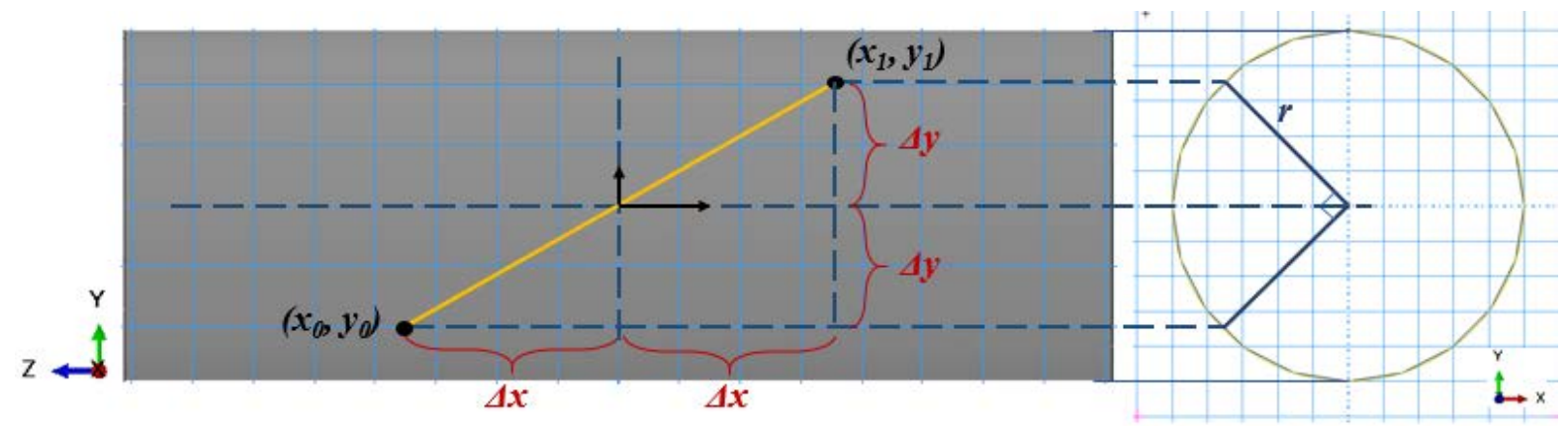

Figure 2 - Modeling of the first reference line that makes the pattern.

$$
\begin{aligned}
& \Delta y=r \cdot \cos 45^{\circ} \\
& \Delta x=\Delta y / \tan \alpha
\end{aligned}
$$

The reference line is repeated along the axial direction of the tube with an offset defined by Eq. 3 (Fig. 3a), and then a new reference line is inserted with coordinates $(-\Delta x,+\Delta y)$ and $(+\Delta x,-\Delta y)$ and new offsets are generated (Fig. 3b). 

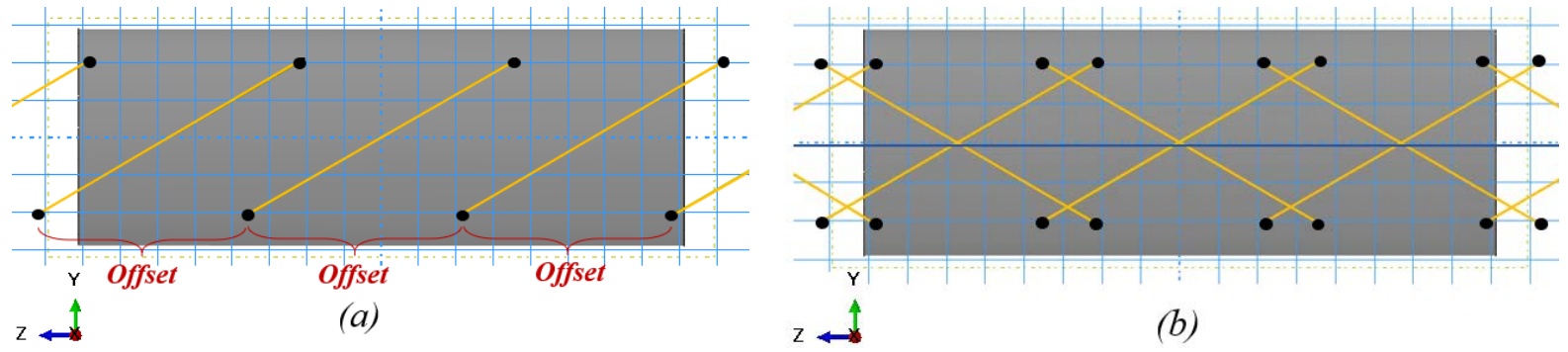

Figure 3 - Drawing of the other lines to compose the desired pattern: (a) offset from reference line, (b) process repeated with a new reference line with other coordinates.

$$
\text { Offset }=8 \Delta x / p
$$

The process of development in datum planes is performed in the other planes, however, in order to continue the helical shape of the winding pattern, the $\left(x_{0}, y_{0}\right)$ point must coincide with the $\left(x_{1}, y_{1}\right)$ point of the previous plane.

\subsection{Winding angle optimization}

A conventional FE model was first developed to determine the optimum winding angle with respect to critical buckling load. The outcome of this model was used as comparison for the results from the models in which the winding pattern was included. The cylindrical shell was modeled as an orthotropic homogeneous angle-ply, and the dimensions of the cylinders were $\phi=50 \mathrm{~mm}$ and $l=140$. A previous work carried out by the group [14] reported that thin-walled cylindrical shells fail due to crushing instead of buckling or material failure, which is not the scope of the current study. Similarly, a hoop reinforcement (20 mm long and $0.21 \mathrm{~mm}$ thick) was wound at the specimen ends to prevent crushing.

The material system used is a carbon/epoxy laminate (Toray T700-12K-50C carbon fiber and UF3369 epoxy resin), and its elastic properties were previously experimentally determined in [15] and used as input in the numerical models (Table 1). The cylinders were modeled using an equivalent single layer (ESL) formulation, with a three-node reduced integration shell element (S4R) with hourglass control. This element is suitable for thinwalled shells and was chosen to reduce simulation time and avoid numerical issues. As boundary conditions, the tube was axially clamped at one end, and a buckling perturbation load in the axial direction was applied on top of the cylinder (Fig. 4).

The linear buckling FE model shown in Fig. 4 is based on Eigenvalue analysis, which demands low computational time. It yields the theoretical buckling strength (bifurcation point) of the structure as output.

Table 1: Elastic constants used in the computational analysis [14].

\begin{tabular}{ccc}
\hline Symbol & Description & Value \\
\hline $\mathrm{E}_{1}(\mathrm{GPa})$ & Longitudinal elastic modulus & 129.3 \\
$\mathrm{E}_{2}=\mathrm{E}_{3}(\mathrm{GPa})$ & Transverse elastic modulus & 9.11 \\
$v_{12}=v_{13}$ & Poisson's ratio in plane 1-2 or 1-3 & 0.32 \\
$v_{23}$ & Poisson's ratio in plane 2-3 & 0.35 \\
$\mathrm{G}_{12}=\mathrm{G}_{13}(\mathrm{GPa})$ & In-plane shear modulus & 5.44 \\
$\mathrm{G}_{23}(\mathrm{GPa})$ & Transverse shear modulus in plane 2-3 & 2.10 \\
\hline
\end{tabular}




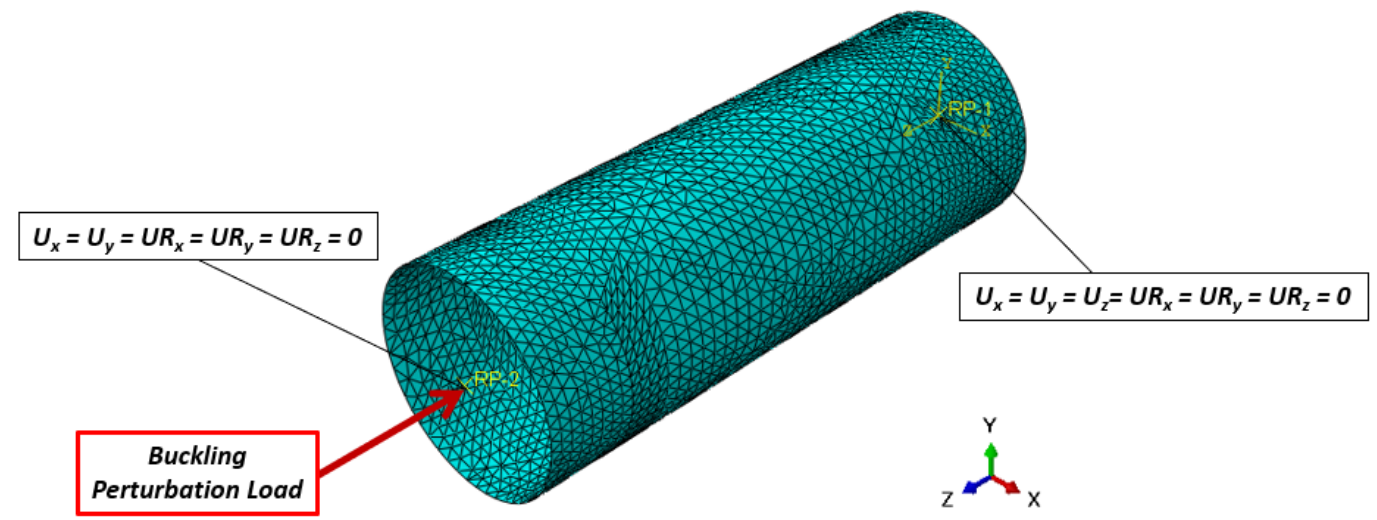

Figure 4 - Tube modeling, boundary conditions and mesh used.

Using the conventional modeling approach (Fig. 1a), the critical buckling load was determined for the winding angle in the $5^{\circ}$ to $85^{\circ}$ range. A Python script was used to perform this, running simulations in the $5^{\circ}$ to $85^{\circ}$ range. Winding angles at $0^{\circ}$ and $90^{\circ}$ were not considered since no winding pattern is formed during manufacturing of these angles, i.e. the band-width is just placed side-by-side.

\subsection{Influence of the Winding pattern FE modeling}

All patterns herein modeled have the same winding angle, which is assumed to be the optimum angle obtained from the procedure described in Section 2.2. Employing the modeling routine described in Section 2.1, the following winding patterns were modeled: 1/1, $3 / 1$ and $5 / 1$. The mesh differs from the conventional model due to the triangular elements, which are more consistent with the format of the partitions (triangular shapes as well). The models with 1/1,3/1 and 5/1 patterns have 39,728, 44,712 and 41,260 elements, respectively, which were defined after a preliminary convergence analysis (see Fig. 7). Fig. 5 shows the models and the manufactured specimens for the various winding patterns.
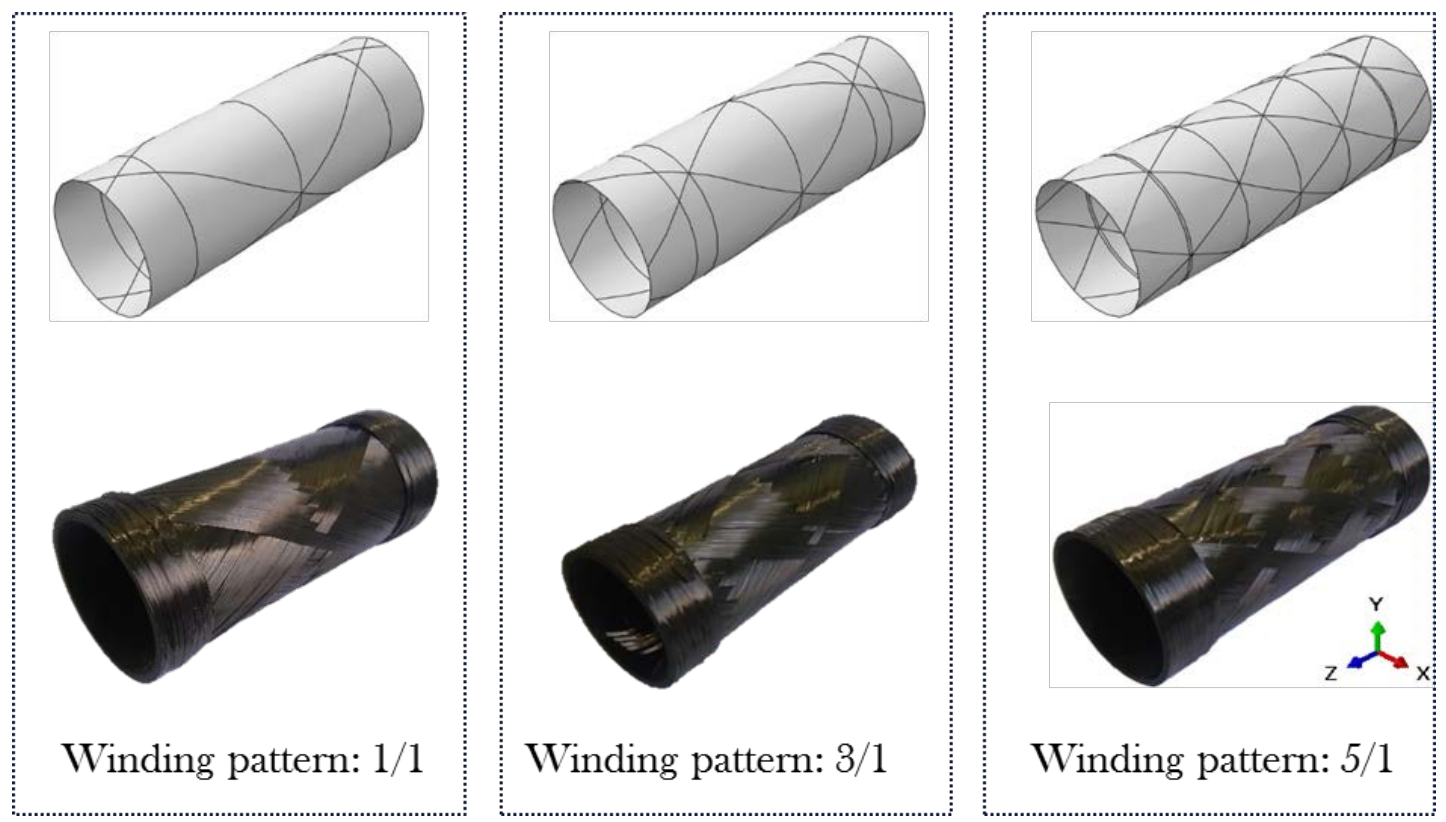

Figure 5 - Modeled and manufactured cylinders with distinct winding patterns. 


\section{RESULTS AND DISCUSSION}

Fig. 6 shows that, for the boundary conditions used, the optimized configuration angle for buckling perturbation load is equal to [ \pm 30 ], where the critical load is $8.57 \mathrm{kN}$.

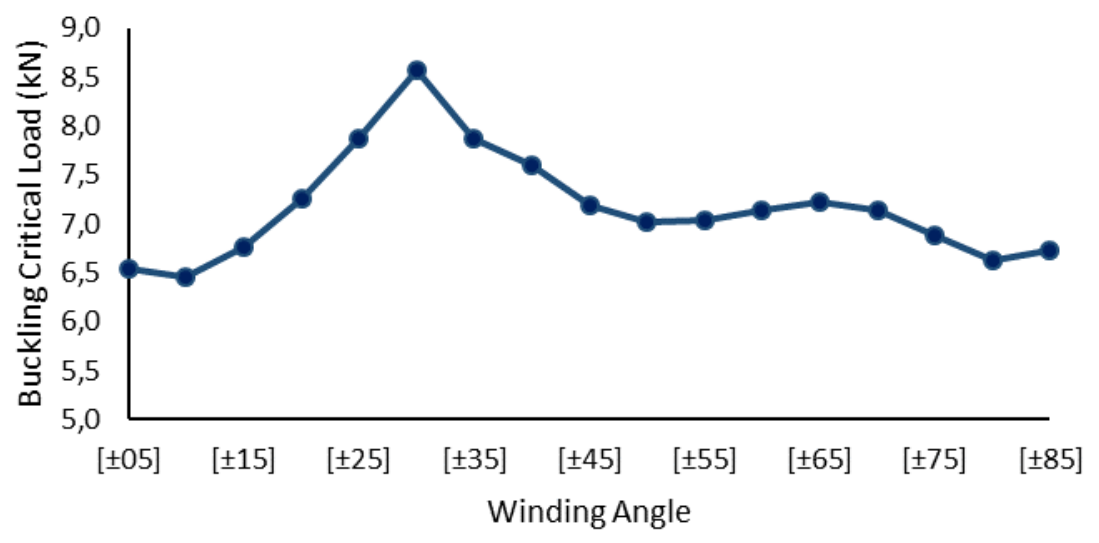

Figure 6 - Buckling load as a function of the winding angle using the conventional modeling approach.

Using the [ \pm 30$]$ configuration, four models were developed: one reference model that does not consider the winding pattern and three models considering different winding patterns. Critical buckling load is very sensitive to mesh density, since buckling is a local phenomenon and may happen suddenly at any point of the structure. In all models, the load converged very well for an element size of $1 \mathrm{~mm}$. The mesh sensitivity analysis is shown in Fig. 7 and the buckled deformed shapes are shown in Fig. 8. As can be seen, the deformations produced in the shells mimic the corresponding mosaic texture.

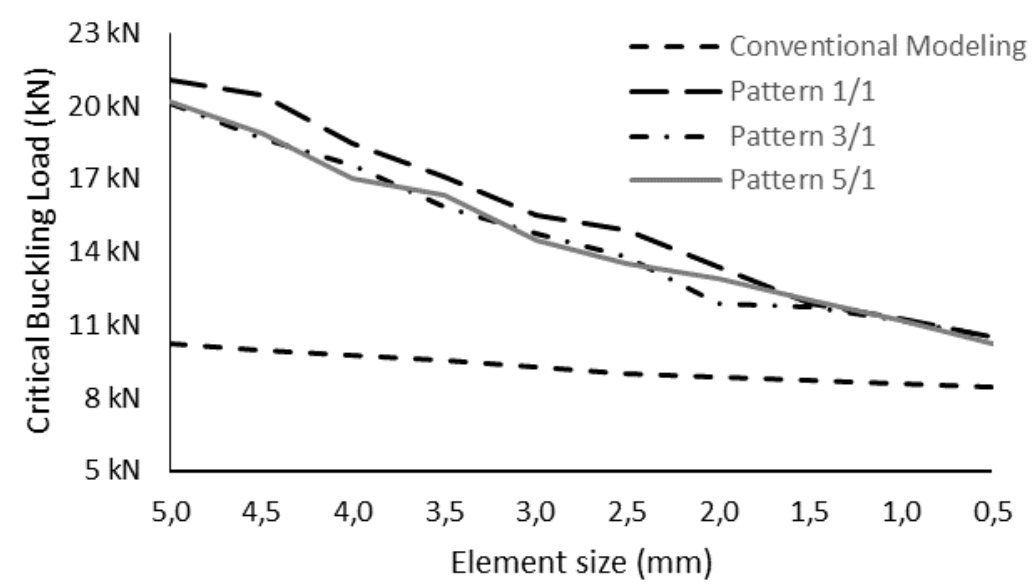

Figure 7 - Mesh convergence analysis.

The overall results for the select meshes are presented in Table 2. Taking into account the winding pattern leads to an increase in critical buckling load of about $30 \%$. However, the variations due to the winding pattern are very small. This may be justified considering that buckling is mostly influenced by the stiffness of the structure and not by the geometrical characteristic of the shell. In that case, non-linear geometrical buckling analysis would be more suitable to achieve more accurate predictions. 

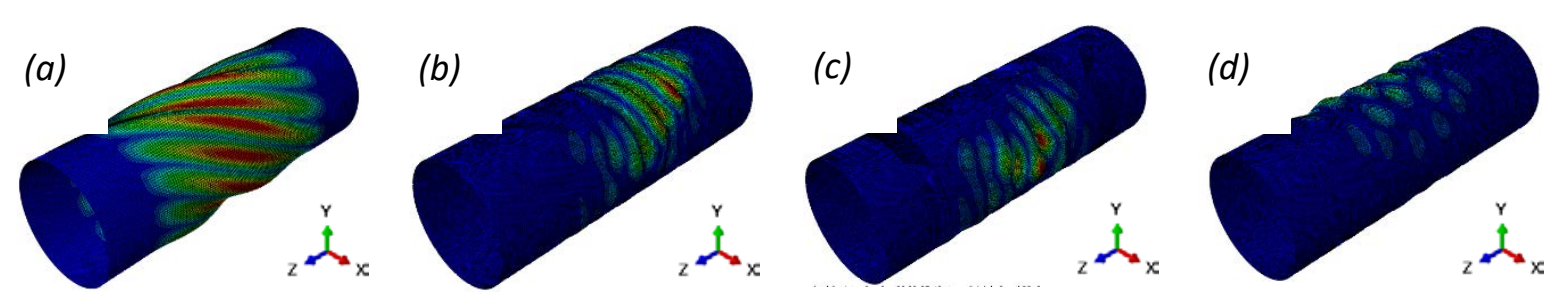

Figure 8 - Buckling shapes of the tubes: (a) No winding pattern modeled, (b) Pattern 1/1, (c) Pattern 3/1, (d) Pattern 5/1 (deformation scale factor: 3×).

Table 2: Predicted critical buckling loads for variable winding pattern.

\begin{tabular}{ccc}
\hline Modeling & Critical buckling load $(\mathbf{k N})$ & Variation \\
\hline Conventional & 8.574 & ---- \\
1/1 pattern & 11.237 & $31.059 \%$ \\
3/1 pattern & 11.173 & $30.313 \%$ \\
5/1 pattern & 11.194 & $30.557 \%$ \\
\hline
\end{tabular}

\section{CONCLUSIONS}

This work presented a methodology to realistically model the filament winding pattern and how those sketches are exported to a FE package. A conventional model considering a nominal angle in the whole structure was built and the optimum winding angle was found and used to model the various patterns studied, 1/1,3/1 and 5/1. A case-study of cylinders under axial compression was evaluated considering linear eigenvalue analysis.

From the linear buckling analysis, an optimum winding angle of $\left[ \pm 30^{\circ}\right]$ was found. It was verified that the critical buckling load was sensitive to the modelling of the winding pattern. The conventional model provided underestimated results, but the variation observed for the various patterns were small for the type of loading considered. Next steps of this work include development of a nonlinear post buckling model and experimental validation.

\section{REFERENCES}

[1] Almeida Jr., J. H. S., Faria, H., Marques, A. T., Amico, S. C., 'Load sharing ability of the liner in type III composite pressure vessels under internal pressure', Journal of Reinforced Plastics and Composites, v. 33(24) (2014) 2274-2286.

[2] Koussios, S., 'Filament Winding: a Unified Approach', PhD Thesis Report, Design \& Production of Composite structures, Faculty of Aerospace Engineering, Delft University of Technology. Delft University Press; 2004.

[3] Dalibor, I. H., Almeida Jr., J. H. S., Costamilan, E., Shynkarenko, O., Amico, S. C., 'Design of a composite nozzle manufactured by filament winding', in 'Aeronautical Composite Materials and Structures - MACMS', Proceedings of a National Conference, São Carlos, Brazil, 2015, 1-10.

[4] Morozov, E. 'The effect of filament-winding mosaic patterns on the strength of thin-walled composite shells'. Composite Structures 76, (2006) 123-129.

[5] P. Krishnan, M.S.A. Majida, M. Afendi, A.G. Gibson and H.F.A. Marzuki. 'Effects of winding angle on the behavior of glass/epoxy pipes under multiaxial cyclic loading', Materials and Design 88, (2015) 196-206. 
[6] Almeida Jr., J.H.S., Ribeiro, M.L., Tita, V. and Amico, S.C., 'Stacking sequence optimization in composite tubes under internal pressure based on genetic algorithm accounting for progressive damage', Composite Structures 178 (2017) 20-26.

[7] Filho, P.S., 'Comportamento mecânico de cilindros de carbono/epóxi processados por enrolamento filamentar para semieixos de transmissão'. Masters Thesis, Programa de PósGraduação em Engenharia de Minas, Metalúrgica e de Materiais, Universidade Federal do Rio Grande do Sul, Porto Alegre, (2016).

[8] Gonçalves, A., Almeida, S.F.M. and Neto, F.L., 'Comportamento de cilindros de carbono/epóxi submetidos a cargas compressivas axiais', Polímeros: Ciência e Tecnologia 11, (2011) 94-101.

[9] Kaynak, C., Erdiller, E.S., Parnas, L. and Senel, F., 'Use of split-disk tests for the process parameters of filament wound epoxy composite tubes', Polymer Testing 24, (2005) 648-655.

[10] Almeida Jr., J.H.S., Tonatto, M.L.P., Gabbardo, F.R.S. and Amico, S.C. 'Resistência à tração circunferencial de anéis de carbono/epóxi produzidos por filamento winding - parte II: análise experimental'. $21^{\circ}$ CBECIMAT - Congresso Brasileiro de Engenharia e Ciência dos Materiais, Cuiabá, (2014).

[11] Rousseau, J., Perreux, D., Verdière, N. 'The influence of winding patterns on the damage behaviour of filament-wound pipes'. Composites Science and Technology 59, (1999) 1439-1449.

[12] Mian, H., Rahman, H., 'Influence of mosaic patterns on the structural integrity of filament wound composite pressure vessels'. International Journal of Structural Integrity 02, (2011) 345-356.

[13] Uddin, Md.S., Morozov, E.V., Shankar, K. 'The effect of filament winding mosaic pattern on the stress state of filament wound composite flywheel disk' Composite Structures 107, (2014) 260-275.

[14] Almeida Jr., J. H. S., Tonatto, M. L. P., Ribeiro, M. L., Tita, V., Amico, S. C., 'Buckling and post-buckling of filament wound composite tubes under axial compression: linear, nonlinear, damage and experimental analyses'. Composites Part B-Engineering. 159, (2018) 227-239.

[15] Almeida Jr., J.H.S., Souza, S.D.B., Botelho, E.C. and Amico, S.C., 'Carbon fiberreinforced epoxy filament-wound composite laminates exposed to hygrothermal conditioning'. Journal of Materials Science 51(9), (2016) 4697-708 